Elżbieta STOKŁOSA ${ }^{1}$, Damian KOLNY²

Opiekun naukowy: Paweł ZIOBRO ${ }^{3}$ Dorota WIECEEK ${ }^{4}$

DOI: https://doi.org/10.53052/9788366249844.20

\title{
InNoWACYJNe TEChNOLOGIE W PRZEMyŚle 4.0 - ROZSZERZONA RZECZYWISTOŚĆ
}

\begin{abstract}
Streszczenie: W artykule przedstawiono nowoczesną, a zarazem innowacyjną technologię poszerzonej rzeczywistości oraz możliwości jej zastosowania w obszarze branży motoryzacyjnej. Omawiane rozwiązanie jest jednym z narzędzi zaliczanych do koncepcji „Przemysłu 4.0”. Stosowanie tego typu podejścia do doskonalenia procesów w przedsiębiorstwie umożliwia osiągnięcie wymiernych korzyści zarówno na poziomie operacyjnym jak i strategicznym, nie tylko poprzez zmniejszenie pracochłonności czy skrócenie czasów przestoju, lecz również zwiększając pozycję konkurencyjną firmy. Wszystkie te czynniki decydują w większym lub mniejszym stopniu o zmniejszeniu ponoszonych kosztów.
\end{abstract}

Słowa kluczowe: Poszerzona Rzeczywistość, Przemysł 4.0, cyfrowa fabryka

\section{INNOVATIVE TECHNOLOGIES IN INDUSTRY 4.0 - AUgMENTED REALITY}

Summary: This article presents a modern and innovative technology of augmented reality and possibilities of its application in the automotive industry. The discussed solution is one of the tools included in the concept of "Industry 4.0". The use of this type of approach to process improvement in the enterprise enables the achievement of measurable benefits at the operational and strategic level, not only by reducing labor consumption or downtime, but also by increasing the company's competitive position.All this factors decide more or less about reducing the costs incurred.

Keywords: Industry 4.0, Augmented reality, digital factory

\footnotetext{
1 Akademia Techniczno-Humanistyczna w Bielsku-Białej, Wydział Budowy Maszyn i Informatyki, kierunek: Zarządzanie i inżynieria produkcji, email: stoklosa.elzbieta6@gmail.com

${ }^{2}$ mgr inż., Akademia Techniczno-Humanistyczna w Bielsku-Białej, Wydział Budowy Maszyn i Informatyki, email: dkolny@ath.bielsko.pl

${ }^{3}$ Właściciel firmy ZPT, email: pawel.ziobro@zp-team.pl

${ }^{4}$ dr inż., Akademia Techniczno-Humanistyczna, Wydział Budowy Maszyn i Informatyki w Bielsku-Białej, email: dwiecek@ath.bielsko.pl
} 


\section{Wstęp}

W publicystyce popularno-naukowej jak i w środowiskach przemysłowych oraz naukowych przyjęło się numerowanie dominujących technologii oraz organizacji wytwarzania, mających związek z kolejnymi przemianami jak i okresami rozwoju produkcji przemysłowej. Otaczające świat czynniki takie jak cyfryzacja życia codziennego, telekomunikacja oraz globalna dostępność produktów, są na ogół zrozumiałe i stanowią powszechny standard. Ostanie lata jednakże znacznie wykraczają ponad przeciętne rozumienie znaczenia tej tendencji, przez rozpoczęcie się kolejnej rewolucji przemysłowej. Etapy rozwoju produkcji w branży motoryzacyjnej wpisują się kolejno w okresy trwania poszczególnych rewolucji przemysłowych. Pierwsza rewolucja miała miejsce w XIII wieku, a jej efektem było rozpoczęcie wykorzystania mocy pary i mechanizacja produkcji. W branży motoryzacyjnej Carl Benz, w 1885 roku, skonstruował pierwszy pojazd z napędem silnikowym. Druga rewolucja w przemyśle nastąpiła w XIX wieku wraz z wynalezieniem elektryczności oraz stworzeniem linii montażowej przez Henry'ego Forda, za sprawą którego rozpoczęła się masowa produkcja samochodów. Trzecia rewolucja przemysłowa została zapoczątkowana w latach $60 . \mathrm{XX}$ wieku poprzez wdrożenie częściowej automatyzacji produkcji za pomocą sterowników z pamięcią oraz komputerów. Dzięki postępowi technologicznemu została umożliwiona automatyzacja całego procesu produkcji [1]. Obecnie trwa czwarta rewolucja przemysłowa, często jest określania mianem „Przemysł 4.0”. Bazuje ona na osiągnięciach poprzedniej - trzeciej rewolucji przemysłowej [2].

Czwarta rewolucja przemysłowa została zapoczątkowana poprzez rozwój automatyzacji, cyfryzacji oraz inteligentnych systemów. Cała koncepcja zależy od rozwoju technologii - systemów teleinformatycznych i cyber-fizycznych, robotyki, technik wizualnych, komunikacji sieciowej [3], [4]. Techniki wizualne składają się z poszerzonej rzeczywistości (AR - ang. Augmented Reality), rzeczywistości wirtualnej (VR - ang. Virtual Reality) i mieszanej (MR - ang. Mixed Reality).

W ostatnich latach ulepszania rozszerzonej rzeczywistości można dostrzec dwie wyodrębnione ścieżki jej rozwoju. Pierwszą jest wykorzystywanie AR we wszystkich możliwych fazach rozwoju produktu: od pomysłu poprzez projektowanie aż do stworzenia finalnego wyrobu gotowego, a także dodatkowo wykorzystanie tej technologii do celów marketingowych. Drugą ścieżką jest wykorzystanie AR do zwiększenia bezpieczeństwa i komfortu jazdy pojazdem - w przyszłości potencjalnie istnieje możliwość, że ta technologia będzie stadium przejściowym pomiędzy pojazdem w pełni autonomicznym, a kierowanym przez człowieka.

Celem artykułu jest przedstawienie możliwości zastosowania innowacyjnej technologii rozszerzonej rzeczywistości w obszarze wsparcia tworzenia, ulepszania i rozwoju procesów oraz wiedzy w przedsiębiorstwach branży motoryzacyjnej.

\section{Rozszerzona rzeczywistość}

Rozszerzona oraz wirtualna rzeczywistość często są ze sobą mylone, lecz łatwo je rozróżnić na podstawie używanego sprzętu. VR należy do urządzeń immersyjnych, czyli takich dzięki którym możliwe jest oddziaływanie na wszystkie zmysły użytkownika - gogle posiadają nieprzeźroczysty wyświetlacz dzięki, któremu 
blokowane jest środowisko rzeczywiste. Sprzęt AR należy natomiast do urządzeń holograficznych - okulary posiadają przeźroczysty wyświetlacz, dzięki któremu możliwe jest zobaczenie środowiska realnego podczas użytkowania.

Oprócz AR i VR istnieje również rzeczywistość mieszana - jest to połączenie dwóch technologii umożliwiające oglądanie wirtualnych obiektów w rzeczywistości, a oprócz tego budowanie doświadczenia, w którym wirtualne oraz realne są praktycznie nie do odróżnienia [5].

Wirtualna rzeczywistość jest to wygenerowany poprzez technologie informatyczne obraz imitujący świat rzeczywisty, w którym dzięki goglom VR oraz dodatkowym elementom jest możliwe całkowite zanurzenie. Użytkownik ma także możliwość wejścia w interakcję ze stworzonym środowiskiem [6].

Rozszerzona rzeczywistość (AR) jest podobna do wirtualnej rzeczywistości, lecz bazuje na jednoczesnym połączeniu świata rzeczywistego oraz wirtualnego - poprzez nakładanie w czasie rzeczywistym wirtualnych elementów na obserwowanych obiektach. Wykorzystywane są do tego aplikacje w smartfonach i tabletach, specjalne okulary, a także gogle.

Rozszerzenie rzeczywistości (AR) jest możliwe dzięki zastosowaniu i odpowiednim połączeniu czterech podstawowych zadań. Podstawowe składowe systemu AR zostały przedstawione na rys. 1.

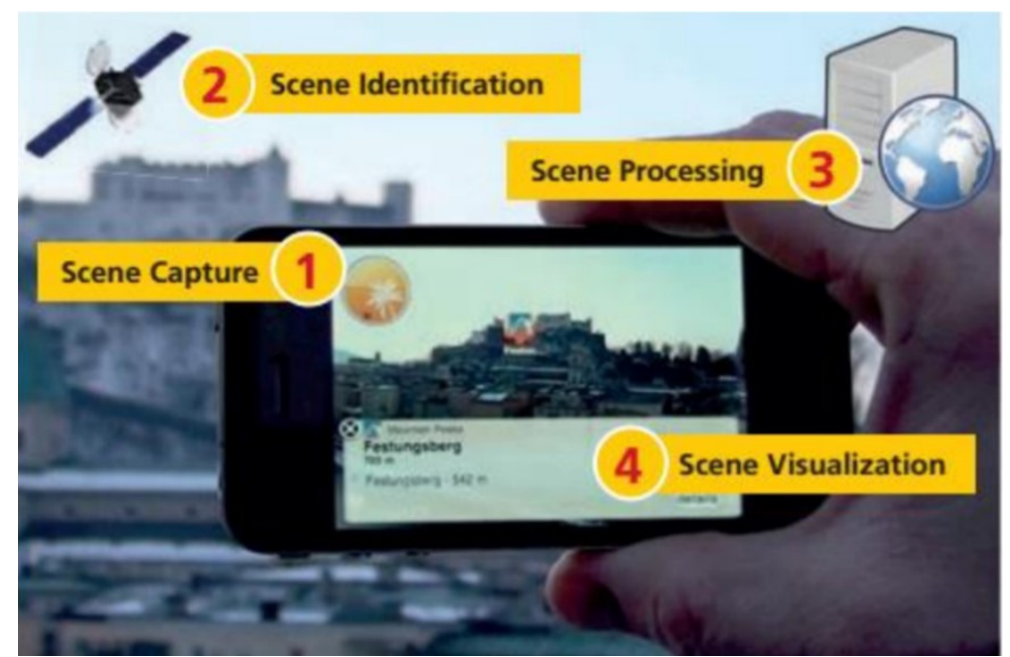

Rysunek 1. Podstawowe składowe systemu AR [7]

Pierwszą składową jest ujęcie obiektu (z ang. Scene Capture) jest to przechwycenie rzeczywistości poprzez sprzęt wyposażony w kamerę np.: smartfon czy tablet. Następnie za pomocą identyfikacji obiektu (z ang. Scene Identyfication) uchwycony obraz rzeczywistości zostaje zeskanowany w celu określenia pozycji, w którym stworzona wcześniej, wirtualna treść ma zostać osadzona. W tym celu wykorzystywane są różnego rodzaju znaczniki wizualne, dzięki którym program może w łatwy sposób rozpoznać przechwyconą rzeczywistość, lub śledzenie, które odbywa się przy wykorzystaniu np.: technologii GPS. Mając już przechwycony i zidentyfikowany obiekt następuje przetworzenie obiektu ( $\mathrm{z}$ ang. Scene Processing) mające na celu wysłanie żądania nadania odpowiedzi do Internetu lub innej 
przygotowanej bazy danych. Na końcu następuje wizualizacja obiektu (z ang. Scene Visualization), która ma na celu nałożenie na przechwytywaną rzeczywistość zwizualizowanych obiektów [7].

\section{Sprzęt do AR - budowa przykładowych okularów}

Najprostszym i najłatwiej dostępnym sprzętem, który można wykorzystać do poszerzonej rzeczywistości jest tablet lub smartfon. W rzeczywistości sprzęt ten ma swoje wady - do jego obsługi potrzebne są wolne ręce, a w wielu sytuacjach np.: podczas montażu są one zajęte wykonywaniem zadanej czynności. Dlatego też wiele firm oferuje specjalne okulary, które wyposażone są w [8]:

- wbudowaną baterię,

- głośniki stereo,

- touchpad do sterowania urządzeniem,

- wejście mikro USB,

- $\quad$ slot na kartę pamięci,

- kamerę,

- mikrofon,

- wyświetlacz obrazu,

- oprogramowanie.

Przykładowe okulary AR zostały przedstawione na rys. 2.

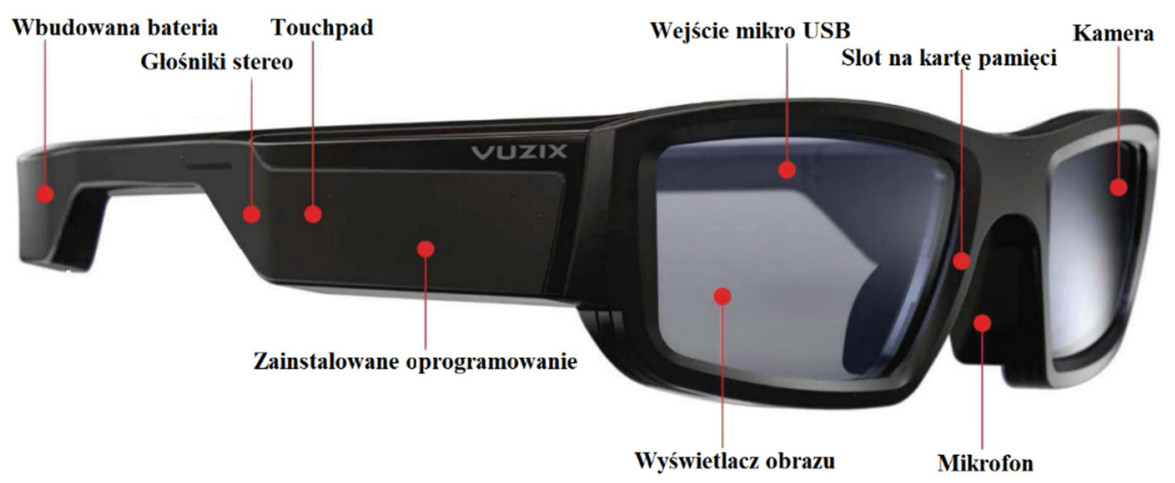

Rysunek 2. Przykładowe okulary AR i ich budowa [8] 


\section{Przykłady wdrożenia AR w przemyśle}

Dzisiejsze techniki wytwarzania stosowane w przemyśle motoryzacyjnym są potencjałem do doskonalenia w wielu obszarach, szczególnie tych cechujących się dużą pracochłonnością, wysokimi kosztami lub ryzykiem. Dodatkowo wymagają zastosowania specjalistycznych umiejętności i wiedzy pracowników. W większości procesy takie jak montaż, kompletacja zamówień czy kontrola jakości wykonywane są ręcznie.

Możliwości zastosowania technologii AR w przemyśle motoryzacyjnym są bardzo szerokie. Dzięki zastosowaniu $\mathrm{w}$ tych procesach poszerzonej rzeczywistości w znaczny sposób jest możliwe wpłynięcie na efektywność pracy, a także zmniejszenie kosztów operacyjnych. Producenci mogą wdrożyć technologie poszerzonej rzeczywistości w swoich fabrykach w bardzo wielu procesach na hali produkcyjnej [4].

\subsection{Projektowanie}

Stworzenie nowej koncepcji czy prototypowanie nowych wyrobów jest zwykle kosztowne i pracochłonne. Wykorzystując do tych czynności technologię AR w łatwy sposób można stworzyć „cyfrowe nakładki” co pozwoli na redukcję kosztów i skrócenie czasu nie tylko samego projektowania, ale także ewentualnych poprawek. Technologię AR można zastosować również w przypadku planowania rozmieszczenia stanowisk - w stosunkowo łatwy sposób będzie możliwy do zobaczenia zaprojektowany układ hali produkcyjnej jak przedstawiono na rys. $3 .[9,10]$

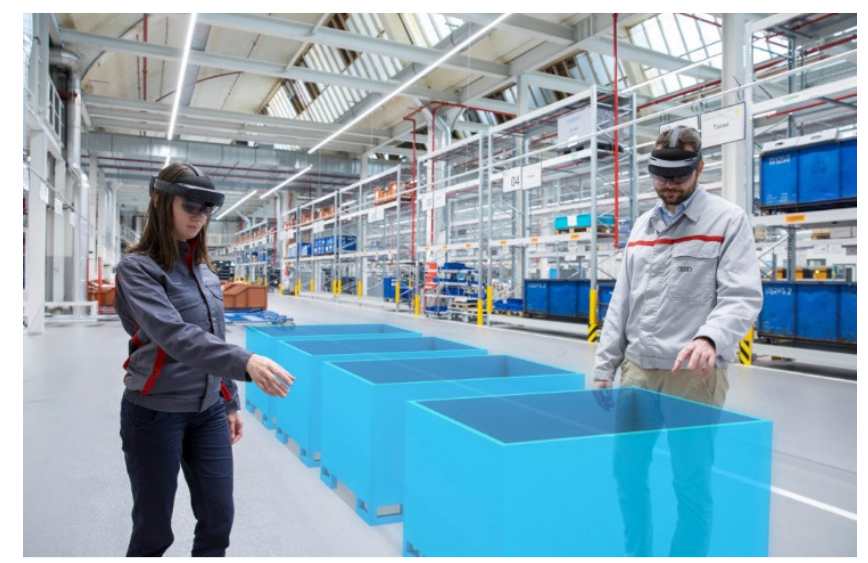

Rysunek 3. Przykład wykorzystania technologii AR $w$ projektowanie rozmieszczenia stanowiska pracy [11]

\subsection{Montaż}

Każdy nowy produkt wprowadzany na rynek wymaga nowego zestawu instrukcji przez co istnieje możliwość pomyłki nawet doświadczonego pracownika. Za pomocą okularów AR pracownikowi prezentowane są na bieżąco, za pomocą grafiki, kolejne etapy procesu montażu - obrazowane są konkretne części, które mają zostać 
zamontowane lub zdemontowane wraz ze wsparciem w zakresie właściwej kolejnością wykonywania czynności. W wielu wypadkach dużo prościej jest stworzyć zrozumiałą dla wszystkich animację, niż instrukcję $w$ formie dokumentacji papierowej. Przykład wykorzystania tej technologii przy montażu przedstawiono na rys.4. [12], [13].

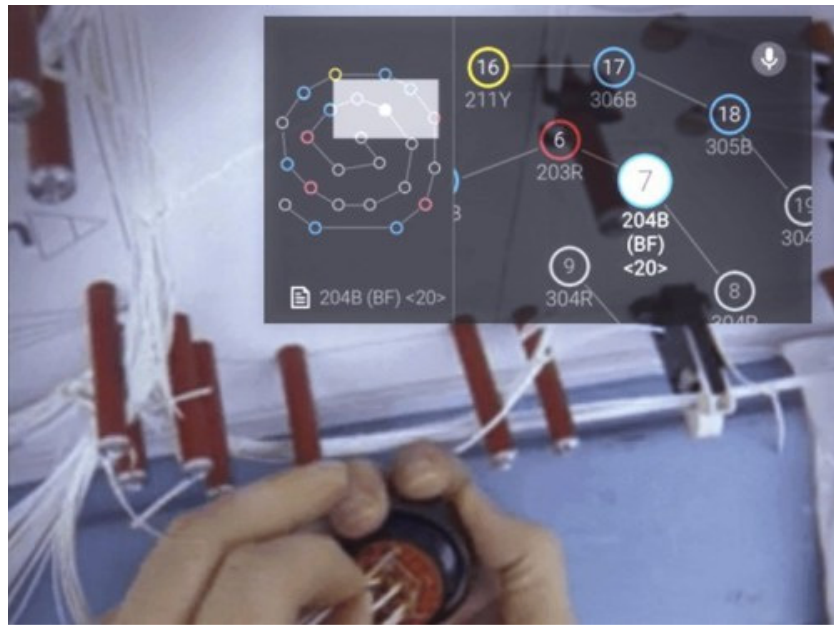

Rysunek 4. Przykład wykorzystania technologii AR - montaż [12]

\subsection{Kompletacja zamówień}

Dzięki zastosowaniu technologii AR podczas kompletacji zamówień pracownik jest w stanie szybciej znaleźć dane produkty na magazynie - nie musi pamiętać dokładnej lokalizacji magazynowania czy sprawdzać w bazie danych, gdzie takowy produkt się znajduje. W zależności od stworzonej aplikacji pudełko, które pracownik powinien zabrać zostanie np. podświetlone na zielono jak pokazano na rys. 5. [14].

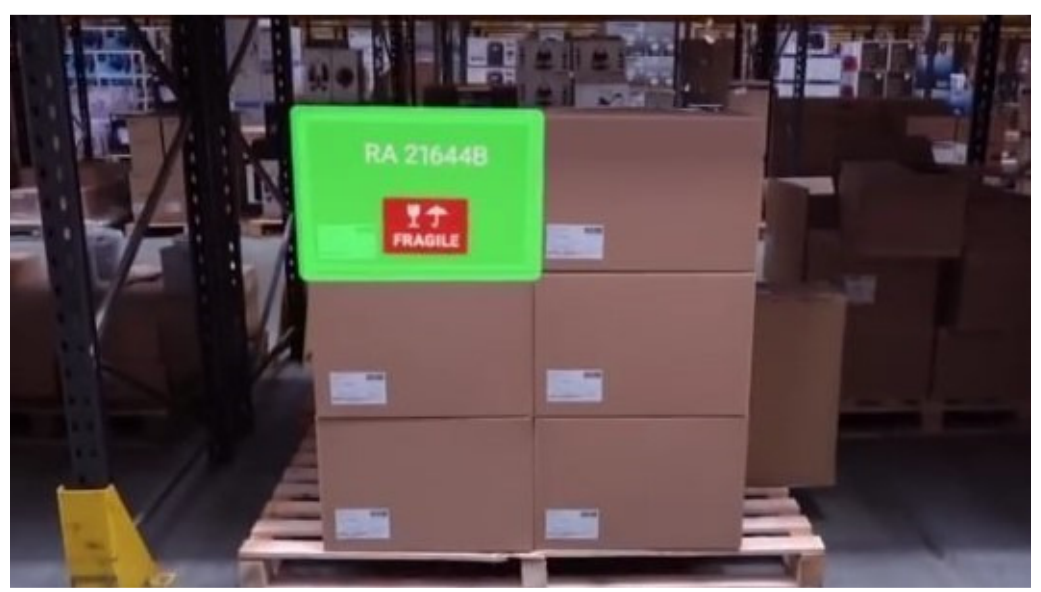

Rysunek 5. Przykład wykorzystania technologii AR - kompletacja zamówienia [14] 


\subsection{Kontrola jakości}

Pracownicy kontroli jakości dzięki technologii AR mogą na bieżąco sprawdzać rysunki techniczne, paramenty, czy poglądowe zdjęcie danego produktu jak pokazano na rys. 6. Jest to pomocne w szybkiej i prawidłowej ocenie jakości i zgodności towaru. Dzięki otrzymywanym w czasie rzeczywistym informacjom, pracownicy nie muszą polegać na swojej pamięci czy tracić czasu czytając papierową dokumentację. Oprócz wygody dla pracowników organizacja zyskuje narzędzie do poprawy jakości. Skuteczna i sprawna detekcja oznacza mniej strat produkcyjnych i reklamacji [15].

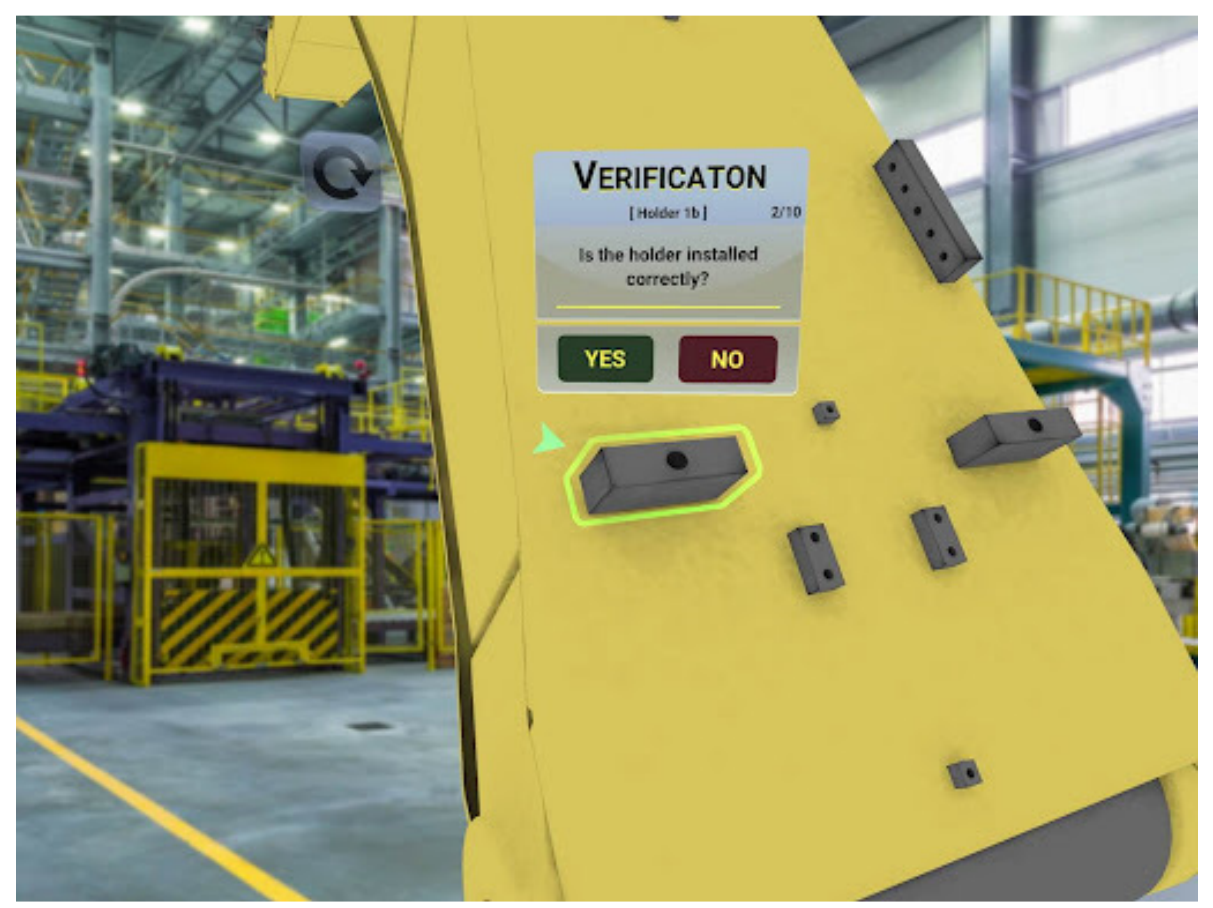

Rysunek 6. Przykład zastosowania technologii AR - kontrola jakości [15]

\subsection{Utrzymanie ruchu}

Rozwiązania poszerzonej rzeczywistości będą bardzo pomocne podczas przeglądów maszyn, diagnostyki czy naprawy sprzętu. Dzięki okularom AR pracownicy mogą otrzymać dokładny opis zadań do wykonania co przedstawiono na rys. 7. Oprócz tego pracownicy mają wgląd do schematów oraz instrukcji urządzeń. Rozwiązanie to wyeliminuje potrzebę posiadania papierowych instrukcji obsługi, co przyspieszy pracę. Dla mniej doświadczonych pracowników będzie to duże ułatwienie [12], [13]. 


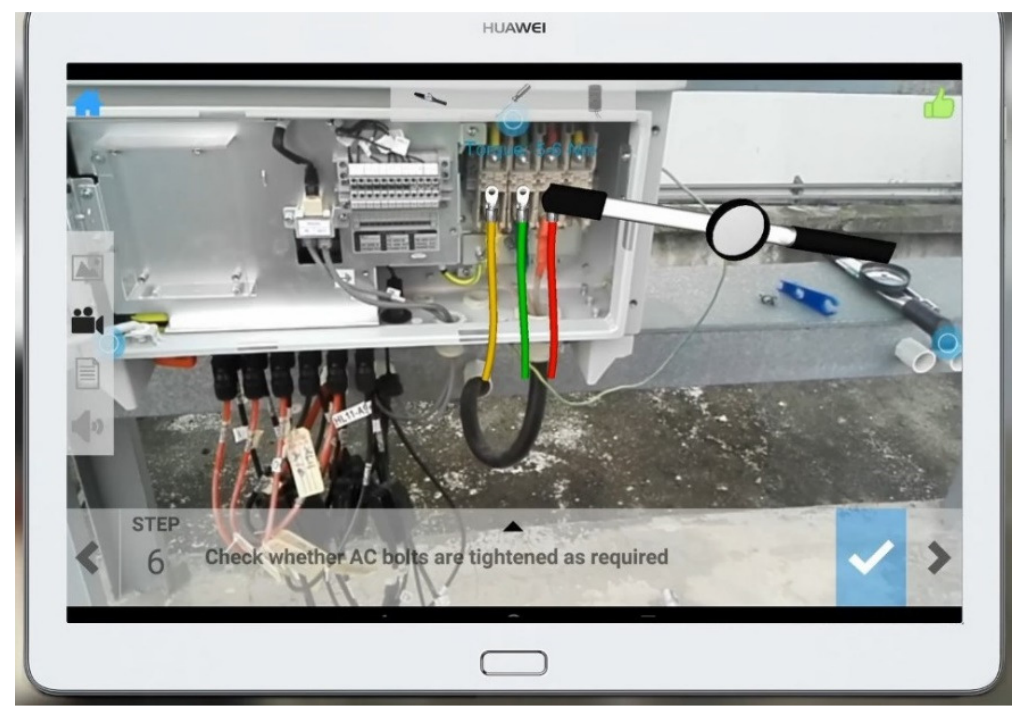

Rysunek 7. Przykład zastosowania technologii AR - utrzymanie ruchu [12]

\subsection{Szkolenia}

W branży motoryzacyjnej dominują szkolenia techniczne związane przede wszystkim z symulacją procesów, które wykonywane są ręcznie. Zwykle szkolenie pracownika w rzeczywistym kontekście oraz standardowymi metodami jest bardzo kosztowne i nieefektywne. Oprócz tego w wielu przypadkach pracownik podczas szkolenia na stanowisku narażony jest na warunki niebezpieczne. Dzięki wykorzystaniu technologii AR proces szkolenia może być bezpieczniejszy, a także zostać zoptymalizowany. Dodatkowo podczas szkolenia nie jest blokowane stanowisko. Możliwe jest nawet szkolenie pracowników bez fizycznej obecności instruktorów jak na rys. 8. [9], [16].

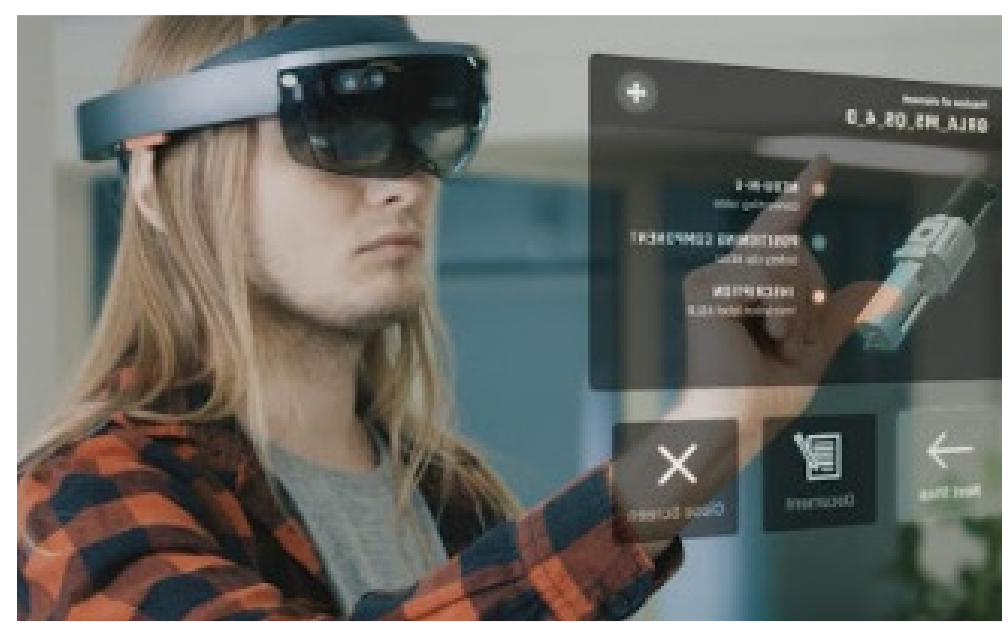

Rysunek 8. Przykład zastosowania technologii AR - szkolenia [16] 


\section{Podsumowanie}

Obecnie trwa czwarta rewolucja przemysłowa, która oznacza zintegrowanie rzeczywistości oraz świata wirtualnego oraz ich łatwą komunikację. Jednym z narzędzi tej rewolucji jest rozszerzona rzeczywistość. Coraz częściej można ją dostrzec w przedsiębiorstwach w branży motoryzacyjnej - posiada wiele zastosowań, a jej odpowiednie wdrożenie może zaoferować wiele korzyści dla przedsiębiorstwa. Łącząc system AR $\mathrm{z}$ istniejącymi $\mathrm{w}$ firmie systemami IT, możemy ciągle aktualizować oraz wyświetlać potrzebne nam dane do wykonywanych działań. Dane te mogą być wyświetlane jako tekst, ale może to być również grafika w postaci wykresu, bądź zdjęcia, animacji czy filmu. Wszystko w tym przypadku będzie uzależnione od przeznaczenia danego rozwiązania, ale także zaawansowania systemu. Rozszerzona rzeczywistość wpływa nie tylko zmniejszenie pracochłonności, a także skrócenie czasów przestoju i awarii poprzez szybką identyfikację problemów i przywrócenie ciągłości procesów - a to wszystko decyduje o zmniejszeniu dotychczas ponoszonych kosztów.

Można założyć, że w przyszłości technologia poszerzonej rzeczywistości będzie nieustannie rozwijana, a co za tym idzie - znajdzie jeszcze więcej zastosowań niż dotychczas.

\section{LITERATURA}

1. STAWIARSKA E., SZWAJCA D., MATUSEK M., WOLNIAK R.: Wdrażanie rozwiązań przemysłu $4.0 \mathrm{w}$ wybranych funkcjonalnych obszarach zarządzania przedsiębiorstw branży motoryzacyjnej: próba diagnozy, CeDeWu, Warszawa 2021, s.21

2. SCHWAB K.: Czwarta rewolucja przemysłowa, Studio Emka, Warszawa 2018, s.13-15

3. Strona internetowa Epic Vr - VR, AR i nowe technologie w przemyśle - jak rewolucja przemysłowa 4.0 zmieni nasz świat?:

https://epicvr.pl/pl/vr-ar-nowe-technologie-przemysle-rewolucja-przemyslowa4-0-zmieni-swiat/, 16.10.2021

4. SKÓRSKA H.: Rzeczywistość rozszerzona narzędziem Przemysłu 4.0 rozwiązania dla branży motoryzacyjnej. Elektronika 6/2019, s.66-69

5. Strona internetowa Microsoft - What is Mixed Reality?: https://docs.microsoft.com/en-us/windows/mixed-reality/discover/mixed-reality, 31.10.2021

6. Strona internetowa VRpoint.pl - Czym jest wirtualna rzeczywistość / Co to jest wirtualna rzeczywistość?: https://www.vrpoint.pl/baza-wiedzy/czym-jestwirtualna-rzeczywistosc-co-to-jest-wirtualna-rzeczywistosc/, 31.10.2021

7. RUSEK D., PNIEWSKI R.: Systemy logistyczne - wykorzystanie rozszerzonej rzeczywistości. Autobusy : technika, eksploatacja, systemy transportowe, 2017, R. 18, nr 12, $1573-1577$

8. Strona internetowa Vuzix - Vuzix Blade Upgraded Smart Glasses: https://www.vuzix.com/products/blade-smart-glasses-upgraded\#/bladetechnical-specs, 31.10.2021 
9. Strona internetowa Automatyka Online - Wirtualna rzeczywistość w przemyśle: https://automatykaonline.pl/Artykuly/Systemy-wizyjne-i-RFID/Wirtualnarzeczywistosc-w-przemysle, 18.10.2021

10. Strona internetowa Internet of business - Augmented Reality in Manufacturing: https://internetofbusiness.com/augmented-reality-in-manufacturing/, 18.10.2021

11. Strona internetowa Przemysł przyszłości - Audi using augmented reality for logistics and production planning: https://www.automotivelogistics.media/news/ audi-using-augmented-reality-for-logistics-and-production-planning/41354. article, 31.10.2021

12. Strona internetowa Przemysł - 4.0 - Rzeczywistość rozszerzona w przemyśle: https://przemysl-40.pl/index.php/2017/05/23/rzeczywistosc-rozszerzona-wprzemysle/, 31.10.2021

13. Strona internetowa Utrzymanie Ruchu - AR i VR w zakładzie produkcyjnym: https://www.utrzymanieruchu.pl/ar-i-vr-w-zakladzie-produkcyjnym/, 18.10.2021

14. Strona internetowa Trans.info - „Augmented reality” in warehouses will be standard in just three years: https://trans.info/en/augmented-reality-inwarehouses-will-be-standard-in-just-three-years-58ef15f8bb04facf158b45ef19159, 31.10.2021

15. Strona internetowa Spectralapplications - Rozszerzona rzeczywistość w kontroli jakości: $\quad$ http://spectralapplications.com/pl/rozszerzona-rzeczywistosc-wkontroli-jakosci/, 31.10.2021

16. Strona internetowa Horyzonty - Nadchodzi przełom w kształceniu pracowników: http://horyzonty.zig.pl/nadchodzi-przelom-w-ksztalceniu-pracownikow/, 31.10.2021 